\title{
The Effect of Advergame as Brand Communication Tool on Brand Consideration and Preference Creation
}

\author{
Servet Gura ${ }^{1}$, Kriselda Sulçaj Gura ${ }^{2}$
}

\begin{abstract}
Advergame is considered as a perfect harmonization between the brand and the branded videogame. Its usage as a brand communication tool creates competitive advantage because it contributes on the effects (short term influence) and effectiveness (long term influence). This method forms, reinforces and alters perceptions thus affecting the creation of brand considerations and preferences. The final act of purchase intention depends exactly on the successful link between the communication instrument and competitive information transmitted. For this reason, this study aims to examine the effect of advergame as a brand communication tool in brand consideration and preference creation. It is conducted a deductive approach. The research material used on it is collected through the Survey and the sample consists of 600 people, clients of "Vodafone Albania" Sh.A from the telecomunication sector in Albania. Differently from previous studies this work uses quantitative method by using SPSS program are quantified the data collected, and test the hypothesis using Ki-square test; finally it does some cross tabulations in order to specify in more details the results using demographic data. Based on the results it may be concluded that inclusion into game increases the positive consideration toward the brand and crates higher brand preferences, moreover, it is seen that it demonstrate continuity effect. The study is the first of its kind in Albania. To date, there is no study which investigates the practice of advergame as a brand communication tool and it recommends adoption of this tool as brand communication strategy on other sectors also. Since the group age of players is expanded it is suggested to be used on different profiles.
\end{abstract}

\footnotetext{
${ }^{1}$ Department of Marketing \& Tourism, Faculty of Economy, University of Tirana, Albania. *Corresponding author.

${ }^{2}$ Department of Banking and Finace, Faculty of Administrative Science, Epoka University, Albania.
} 
Key Words: Advergame, brand communication tool, brand consideration, brand preferences 